\title{
CDR Entry Completed by (signature)
}

National Cancer Institute

\section{Source}

National Cancer Institute. CDR Entry Completed by (signature). NCI Thesaurus. Code C157094.

A directive to add the signature of the individual completing the Comprehensive Data Resource (CDR). 